\title{
Estampas de la vida judía y sus particularidades: Huesca, siglo XV
}

Eugenio Benedicto Gracia

Se presentan en este artículo varias escenas singulares de la vida cotidiana de los judíos de Huesca y de su aljama a lo largo del siglo xv ilustradas a través de documentos extraídos de protocolos notariales y que hacen referencia a aspectos relativos a las relaciones familiares, la vida social y la condición femenina.

Palabras Clave: historia de los judíos; Aragón; Edad Media; vida cotidiana.

Sketches of Jewish Life and its Peculiarities: Huesca, 15 ${ }^{\text {тн }}$ Century. - Daily life scenes and documents concerning Jews in the city of Huesca during the fifteenth century illustrated through textual evidence extracted from notarial protocols dealing with divers aspects concerning familial relationships, social life and the status of women.

KeYwords: History of the Jews; Aragon; Middle Ages; Daily Life.

Este artículo incluye el primer grupo de una serie de documentos notariales relativos a los judíos de Huesca que, por su contenido, no es posible ordenar con un criterio unitario'. La heterogeneidad de los mismos abarca desde un jugador compulsivo; una riña matrimonial; la reparación del baño (o micvé) de las mujeres; el establecimiento de una panadería dentro del barrio judío; la devolución de una hija a su padre; la negativa a amamantar a un recién nacido por su madre; la promesa de cesar en el concubinato con una barragana; y, finalmente, la relación de parte de los bienes que obliga a devolver la Inquisición a un recién convertido.

1 Con anterioridad, y utilizando fuentes notariales, he estudiado diferentes aspectos de la vida de la aljama de los judíos en Huesca durante el siglo xv: «La aljama de los judíos de Huesca a finales del siglo xv: La nómina de casatenientes de la judería de 1475», Sef 63 (2003), págs. 227-236; «El asesinato en 1465 de Jehudá Alitienz, de la judería de Huesca», Sef 65 (2005), págs. 287-325; «Documentos acerca del funcionamiento del sistema de insaculación en la aljama judía de Huesca (siglo xv)», Sef 66 (2006), págs. 309-343; y «Los médicos judíos de Huesca, según los protocolos notariales del siglo XV», Sef 68 (2008), págs. 55-87. 
El judío Juceff Maçó se obliga ante el notario Juan de Azlor y Sancho Pérez de Muchascasas, de Huesca, a no jugar a juego en el que haya dinero durante un periodo de cinco años y en un radio de diez leguas (ó $55 \mathrm{~km}$ ) alrededor de la ciudad, incluida esta. Los compromisos y juramentos que se conocen en otros $\operatorname{casos}^{2}$ se realizan ante el mismo juramentado y el notario, pero aquí aparece además un tercero, Sancho Pérez. Cabe la posibilidad, aunque no es seguro, que este fuera el encargado de controlar las tahurerías, función concedida por el rey a algunos individuos, lo que hace pensar que podría conocer las «habilidades» del jugador profesional y lo «echa» de Huesca. No obstante, es posible también que se tratara de un acreedor suyo. Es probable que Maçó procediera de Jaca ya que este apellido no aparece documentado en Huesca ${ }^{3}$.

\section{7, septiembre 27}

El judio Juceff Maçó se compromete a no jugar por un periodo de cinco años.

Archivo Histórico Provincial de Huesca (en adelante, AHPHuesca), prot. 2878 (notario Juan de Azlor), f. ${ }^{\circ} 54$.

Actum Osce. XXVII septembris, 1397

Como yo Juceff Maçó, judío Osce, prometo, conviengo, me obligo a vos, Sancho Pérez de Muchascasas Osce, de non jugar a ningún juego que dinero hí avrá por tiempo de cinquo anyos primeros venient en la ciudat de Huesca ni por spacio de diez leguas alderedor, e en caso de trobado seré, por cada una vegada que provado legítimament, que encora en pena de doze florines de oro, de la qual pena serán los diez florines pora la obra de los muros de la ciudat de Uesca, un florín pora vos, dito Sancho Pérez, e el otro florín por al acusador, la qual pena los jurados qui son e serán. E vos, dito Sancho e acusador puedan sacar de mis bienes de part alguna por los justicia e bayle qui son con amplius dapnis.

Testes: Johan de Exea, coredor, e Jucé Avingastón, judío Osce.

2 A. Blasco, «Los judíos de Aragón y los juegos de azar», Aragón en la Edad Media 14-15 (1999), págs. 91-118.

${ }^{3}$ Referencias a David Maçó de Jaca (1467) en J. CASTAÑo, «Ketubbot en-cubiertas: fuentes para el estudio del matrimonio judío en Jaca y los Almosnino», Sef 69 (2009), págs. 43-73: 70-72. 
Casi quince días después de la riña con su marido, Mira acude al notario y deja constancia que «abssuelvo, quieto e defenesco al dito marido mío de cualquier demanda qu'él podiés facer», tanto ella o cualquiera por ella, «como aquel que no me tiene culpa, ni me tocó, ni me firió». Parece que el daño que dice que se causó escapando de su ira, ha trascendido y probablemente va a ser denunciado, bien ante las autoridades judías o ante las cristianas con posibles consecuencias penales para Sacón. Tanto la justicia de los judíos como la de los cristianos eran duras con el culpable de derramamiento de sangre en cualquier riña. A fin de que su marido no fuera juzgado ante el tribunal cristiano -lo que llevaría a su inculpación según el Fuero-, ella misma se acusa del daño. Es patente que la pareja no funcionaba bien y que si la situación entre ellos se agravaba, ella podría ser implicada en una encuesta como provocadora de la agresión. El suceso tiene lugar durante la Pascua de Cabañuelas en que «s'enoviassen [sic, ¿por s'enoiassen?] e se haviesen barullado», infringiendo ruidosamente el precepto de šalom bayit ('paz en el hogar') ${ }^{4}$. No ha sido posible identificar en la documentación notarial el matrimonio, aunque el apellido del marido (Allpebech, ¿por Alpellent?) aparece en muy contadas ocasiones.

\section{0, octubre 12}

Mira, mujer de Sacón Allpebech, disculpa a su marido del daño que se ha hecho en su cabeza al salir precipitadamente de su casa, después de que hubieran discutido durante la comida sabática, tras lo cual el marido intentó agredirla.

AHPHuesca, prot. 6366 (notario Sancho Soas), f. ${ }^{\circ} 42 v$.

Díe martes XII octobre. Osce.

Die quo supra. Yo Mira, muller de Sacón Allpebech, judía Osce, present mí, notario e los testimonios dius scriptos, fue constituída personalment et propuso et dixo que día sábado primero passado, que se contaba IX mense, e avin presentes ellya e el dito marido suyo, stando a taula s'enoviassen e se haviessen barallyado, et el dito marido suyo la queries ferir, e ellya esto veyendo quiso fuir e exir de hun palacio do comían, e al sallyr de la puerta del palacio, que sallía rescia, entropeçó et cayó et dióse de la cabeça en la açarbea de la puerta del palacio. Et por esto yo, de mi cierta sciencia, absuelvo quieto e

${ }^{4}$ De hecho, el 12 de octubre de 1400 coincide con el 22 de tišrí, šeminí așéret, día final de la Pascua de las Cabañuelas,

5 Jucé y Lop (1393); Mossé (1402); cf. A. Duran, La Judería de Huesca (Zaragoza 1984), págs. 49 y 159. 
defenesco al dito marido mío de cualquier demanda qu'él podiés facer yo ni otri por mi, como aquel que no me tiene culpa ni me tocó, ni me ferió, requeriendo al notario dius scripto que l'ende fiziés carta pública.

Teste: Pasqual de Bierche, barbero et Açach Alguer, judío Osce.

La legislación rabínica relativa al baño ritual está relacionada con las categorías religiosas de «puro»e «impuro». Dicho precepto no se refiere únicamente a la mujer, siendo la impureza femenina resultado tanto de la menstruación como del parto, o bien como resultado de tocar un cadáver o un objeto impuro, sino también al varón. Incluso, los utensilios utilizados de manera cotidiana debían ser sumergidos antes de su primer uso, en caso de que hubieran sido fabricados por no judíos. El micvé o baño ritual es una exigencia halájica desarrollada principalmente en la Mišná ${ }^{6}$ y debe ser frecuentada tanto por mujeres como por varones por respeto a las reglas de pureza, y no por simples necesidades de higiene. Del documento presentado aquí conocemos que la aljama de judíos de Huesca poseía un micvé con anterioridad a la mitad del siglo XV.

El 17 de septiembre de 1448 don Mossé Argellet y el piquero Miguel de Ernialde firman la reforma del «banyo de mulleres» ${ }^{7}$. Lo primero que podríamos preguntarnos es si dicho baño es propiedad de Argellet o pertenecía a la comunidad judía. Cuando se trata de propiedades particulares lo frecuente es que los documentos describan sus linderos, y en este caso se limita a citarlos de forma general: «sitiado en la judería [...] dentro en huna caseta del dito huerto». Ello indicaría que se trata de un baño de la aljama, y que don Mossé actúa como representante de la misma.

Con frecuencia, cuando se tenían que hacer obras o gestiones de importancia se nombraba a un individuo de prestigio y Mossé Argellet, perteneciente a una de las familias judías más adineradas de Huesca ${ }^{8}$, aparece representando en varias misiones a la comunidad judía. Así, el 5 de septiembre de 1457 es su procurador ante el Rey ${ }^{9}$.

${ }^{6}$ La Misná, ed. C. del VALLE (Salamanca 1997²), págs. 1323-1345.

7 Respecto a la especificación «de mujeres», cf. D. Romano, «Baño o miqwé de Lérida (1339)», Sef 35 (1975), pág. 158.

${ }^{8}$ Cf. Durán, La Judería de Huesca, pág. 81.

9 AHPHuesca, prot. 63, f. $73 \mathrm{v}$. 
La reforma propuesta consiste en dar al baño un palmo más de profundidad de la que tiene en ese momento. Para ello es necesario reformar el baño actual y darle la capacidad necesaria para que, por lo menos, cupieran cuarenta śeot (entre 500 y 800 litros, según las interpretaciones).

Las condiciones técnicas son las normales en una obra de piedra: la cara interior de los sillares debería ser pulimentada con un buen acabado y la parte exterior del muro del baño sería rehecho con los materiales que salieran del recipiente antiguo. No se especifica cómo se rejuntarán los sillares para que no tengan pérdida de agua ya que la cal permitiría al poco tiempo su fuga. Puede ser que sellaran con cera las juntas de la piedra.

El piquero ha de tener el baño lleno durante un mes y «abenarlo» ('vaciarlo') después en un día, a fin de probar su estanquidad. Hay que tener en cuenta que el llenado del baño podría hacerse con el agua de la acequia principal que corría por la judería de norte a sur y que se dispondría de un tiempo muy justo para proceder al vaciado y llenado con cargo a dicha acequia. En el lugar que ocupaba la judería de la ciudad no se conoce toma de aguas subálveas alguna. Y teniendo en cuenta la climatología local, habría sido bastante difícil llenarlo con agua de lluvias.

Como era casi tradicional, el propietario tenía que facilitar los materiales necesarios para la obra. En realidad, el contrato se formalizaba en relación a la mano de obra, más que por el material empleado en ella. No obstante si la obra no funcionaba adecuadamente y fallaba en su finalidad, el piquero venía obligado a rehacerla y en este caso todo correría a su cargo. Esta cláusula era muy común y siempre se dejaba a criterio de maestros elegidos por el justicia.

Se establece que el plazo de la obra será de un mes aproximadamente. El piquero recibirá cien sueldos, que podrían ser un anticipo; además, se le concede un préstamo de 506 sueldos a devolver en julio de 1449. El acuerdo de reforma está fechado el 17 de septiembre de 1448 (18 de tišrí), que corresponde al periodo de hol ha-mo'ed de la Pascua de las Cabañuelas, es decir, pasadas las principales festividades del inicio del año judío.

\section{8, septiembre 17}

Capítulos de reforma del baño (micvé) de las mujeres situado dentro de la judería concordados entre don Mosé Argellet, en representación de la aljama, y el piquero Miguel de Ernialde.

AHPHuesca, prot. 88 (notario Juan de Ara), f. ${ }^{\circ} 273 r-274 v$. 
Capítoles concordados entre don Mosé Argellet e Miguel d'Ernialde. Eodem die, Osce. En los capítoles infrascriptos, Miguel d'Ernialde piquero prende a stallyo del dito don Mosé vna obra de hun banyo de mullyeres, el qual ha de faser dentro en hun huerto sitiado en la judería de la dita ciudat, dentro en huna caseta del dito huerto.

Primerament, el dito banyo a seyer más fondo de aquello que agora yes hun palmo.

Item, el dito Miguel lo ha de fazer de piedra picada, la cara de la agua, e de la otra part de fuera de reble todo alderredor del banyo, del suelo entro al canto alto.

Item más, qu'el dito Miguel sía tenido meter toda aquella piedra e reble entre sitios que será necesario en la dita obra vltra aquella piedra que agora yes en el dito banyo.

Item, qu'el dito Miguel sía tenido dar el dito banyo tenient aprés que hun mes será seydo abenrado de hun día ${ }_{273 v}$ cada semana que será enplido d'ally adelant, menos de meter agua lo haya a dar, tenient pleno, tienpo de quatro meses.

Item más, qu'el dito Miguel sía tenido dar feyta la dita obra d'aquí a mitant el mes de octobre primero venient.

Item, qu'el dito don Mosé yes tenido dar e da luego de present al dito Miguel por razón de la dita obra cient sueldos, los quales Miguel atorga hauer luego recebidos del dito don Mosé e lende atorgó albarán.

Item más, el dito don Mosé yes tenido dar en ayuda de la dita obra toda la cancina e arena que ý será necesaria.

Item más, yes condición que si la dita obra fallyrá e no la havrá feyta segunt yes tenido fazer ${ }_{274 \mathrm{r}}$ de partes de suso, que en el dito caso el dito Miguel sía tenido tornar a fazer la obra a propias mesiones suyas de piedras maestras, calcina, arena e todas las ditas otras mesiones que necesarias serán, segunt partes de suso yes contenido, a conexenca de dos maestros esleyderos por el justicia de la dita ciudat. E por la dita razón el dito Miguel obligó su persona e bienes.

Testes: Arnalt de Montín e Jucén Samarel, judio habitante Osce.

Eodem die Osce, el dito Miguel d'Ernialde, juró a Dios, e a los santos Quatro Evangelios de dar e pagar al dito don Mosé cincientos e setze sueldos dineros jacceses, pagaderos d'aquí por todo el mes de julio primero venient del anyo XXXXVIIII' ${ }^{\circ}$, subpena super juri o pasar con su voluntad, la qual coste por carta pública. Testes qui supra.

4

El siguiente documento da a conocer un acuerdo entre los jurados y el Concejo de Huesca con los adelantados de la aljama judía para el establecimiento de una «panicería» dentro del barrio judío. Se permite establecer una panadería 
judía, exenta del régimen general de panaderías de la ciudad, y además se acordaba que el concejo tuviera dentro de la judería una panadería que vendiera a todos. La comunidad judía debía carecer de panaderia propia, pues dice el primer punto «si quiere de la dita aljama, puedan poner, fundar y tener su panicero judío»; luego no tienen en ese momento «fundada panaderia judía».

Los dirigentes de la comunidad judía no podrían prohibir a ningún judío la compra de pan en la panadería cristiana. Tampoco se podría impedir que los judíos compraran la harina y las «pueyas» de masa sobrantes para poder amasar el pan para el día siguiente. Es inusual que el documento no termine con los correspondientes testigos, lo que hace sospechar que se trata de una copia del original que no llegara a ser concluida completamente.

\section{5, octubre 23}

Los jurados y Consejo de Huesca y los adelantados de la aljama concuerdan los capítulos que han de regir en la panadería que se pretende abrir en la judería y que daría servicio a cristianos, pero también a judios y a moros.

AHPHuesca, prot. 289 (notario Antón Bonifant), f. ${ }^{\circ} 107$ r.

\section{Jhesus Cristus}

Capítoles fechos e concordados entre los magníficos senyores, los jurados e Consellyo de la ciudat de Huesca de la una part y los adelantados de la aliama de los judíos de Huesca y la dita aliama de la otra, en et sobre la panicería de la dita judería e otras cosas acerqua de aquellyas:

[1] Primerament, es concordado entre las ditas partes que los judíos de la aljama de Huesca, si quiere de la dita aljama, puedan poner, fundar y tener su panicero judío en la dita judería a voluntat de la dita aljama perpetuamente así por asignación, elección, nominación, como por vía de rendación en otra qualquiere manera, según bien visto le será, el qual panicero asignado o rendador liberament e sin impediment alguno de la dita ciudat, ni oficiales e singulares de aquellya, pueda vender pan de qualquiere natura y al precio y peso que bien visto será a la dita aljama así dinarales como dobleros e quadernas e qualquiera otra faría de pan. El qual pan empero, el dito judío panicero asignado o rendador no pueda vender sino a judíos habitantes en la dita ciudat e a otros qualesquiere que venrán en aquella que sían judíos, e si el contrario fará, encorra por cada vegada en pena de sixsanta sueldos adquirideros a la bolsa de los jurados que son o por tiempo serán, la qual pena sía executada del contrario facient adjudicada havida verdadera información.

[2] Item, es concordado que'l dito judío panicero asignado o rendador, qui es o por tiempo será por la dita aljama, ni la dita aljama por tener al dito panicero, no sían 
tenidos de dar ni responder de cosa alguna a la dita ciudat ni a los arren- ${ }_{107 \mathrm{v}}$ dadores de las panicerías de aquellya ni a los oficiales ni a otra persona alguna de la dita ciudat por vía de gracia ni por otra alguna exacción directament ni indirecta, antes liberament e sin empacho alguno puedan tener el dito panicero asignado o rendador qui será de la dita panicería, usar de la dita panicería en la forma de suso dita, sinse impediment ni contradicción alguna a uso de judíos como dito es e no en otra manera, jus la dita pena.

[3] Item, es concordado entre las ditas partes que la dita ciudat pueda tener en la dita judería panicero o rendador de panicerías el qual puedan vender pan a los judíos, moros, cristianos, liberament, dinerales, dobleros, quadernas.

[4] Item, es concordado que la dita aljama por tiempo alguno no pueda vedar directament o indirecta ni por otro empacho alguno ni en qualquiere manera requisita a d'algún judío de la dita aljama ni a otro judío alguno que no compren pan del panicero cristiano, antes sía e finque en libertat de cada un judío si querrá comprar del panicero cristiano o judío, del qual más le plazerá; no obstant, qualquiere ordinación por la dita aljama feyta o fazedera, e no res menos, la dita aljama encorra en pena de cincientos sueldos por cada vegada que en contrario de lo sobredito ordenará, jus la pena levadera ut supra.

[5] Item, es concordado entre las ditas partes que la aljama pueda tener, asignar aquellas persona o personas que visto les será, pora vender farina o farinas a los singulares de la aljama que son o por tiempo serán e no a otro alguno sinse empacho ni impediment alguno por los oficiales de la ciudat ni alguna otra persona de aquellya, dadero jus la dita pena executadera ut supra.

[6] Item más, es concordado que'l fornero o forneros qui son o por tiempo serán en dita judería, puedan vender las pueyas quen'l dito forno plegarán con dos quartales de farina más por cada un día, la qual puedan mesclar ensamble con la dita pueya con que sía pastada cozida la dita farina, el qual pan no pueda vender sino a judío, jus la pena levadera ut supra.

Samuel Landié, sastre de la aljama de Ayerbe, acude en 1480 por segunda vez ante los dayanes de la aljama judía de Huesca (don Gentó Argellet y maestre Açach Xuén) para pedir que le sea devuelta su hija. El documento guarda discreción y calla aspectos fundamentales de la situación. Por ello, cualquier interpretación es hipotética: ¿Hay en el trasfondo un divorcio que no acaba de consumarse? Cabe la posibilidad de que el marido no quisiera entregar a su mujer la dote que esta aportó al matrimonio, condición imprescindible para que el divorcio se llevara a cabo. Por otra parte, ella no abandonaría el hogar para 
no ser declarada en rebeldía, por lo que encarga a su padre (Simuel Landié) que gestione su libertad. No podemos ignorar que él cuenta entre los testigos con el abogado (consídico) Johan d'Ipas.

Los dayanes piden a Samuel que no cierre la carta, que ellos « fesen citar ad aquel que su fillya tenía e que le farían justicia». No lo llaman marido ¿Es que la situación que imaginamos esconde otro asunto? Difícilmente lo llegaremos a averiguar.

1480, marzo 20

Simuel Landié judio de Ayerbe, pide a los dayanes de la aljama de Huesca que tomen las acciones necesarias para que su hija le sea devuelta.

AHPHuesca, prot. 317 (notario Blasco Colduras), f. ${ }^{o} 58$ r.

Carta pública. A vint del mes de março, Osce, anyo $\mathrm{M}^{\circ} \mathrm{CCCC}$ e guytanta, delant los honorables don Gentó Argellet e maestre Açach Xuén, mege, dayanes de la aliama Osce, comparesció Simuel Landié, judío sastre, vezino de la alyama de la villya de Ayerbe, a los quales como dayanes suplicó e requirió que le ficiessen dar su fillya. En otra manera, que atendido que ya havíen estado ocho dias que conocer fablando, que protestava de todo aquellyo que cierto es que ellyo e protestar [sic]. E los ditos dayanes demandaron copia e que no cerasse la carta pública sienes respuesta. Los ditos dayanes dixeron que fesen citar ad aquel que su fillya tenía e que le farían justicia. Testes: Johan d'Ipas, consídico, e Junez Azaz, texidor, e Habran Gastón, texidor Osce.

6

Ante el conocido notario oscense Domingo Frayella, el lugarteniente de adelantado de la aljama de los judíos Salomón Anoqua y otro adelantado más, toman testimonio de la situación que se plantea a la muerte de Salamón Çurí, judío de la aljama de Huesca, ya que su mujer, Solí Carnerón, que había estado embarazada, da a luz a un niño, al que poco después se niega a darle de mamar y a criar porque «deliberaba» casarse de nuevo. Esta es la versión que dan los parientes del difunto Salomón Çurí. Los adelantados quieren averiguar lo que realmente ha pasado en relación a este asunto y convocan al hermano del fallecido, Mossé Çurí, un judío de Uncastillo, además de al judío oscense Leví Yayón, encargados de informar al rey y a otros jueces de lo que ha ocurrido en relación con este niño. 
Mossé Çurí ratifica la versión anterior y añade que, ante la situación en que queda el niño y antes de que se «pierda», ha decidido llevarlo a Uncastillo y entregarlo a su abuela para que lo diera a criar. El viaje era dificultoso por la distancia, aproximadamente de $100 \mathrm{~km}$ y aunque hasta Ayerbe el camino era llano y sencillo, desde allí en adelante hasta Uncastillo se volvía complicado y difícil, por lo que no es extraño que buscara otro judío que le ayudara.

Resulta difícil aceptar que la madre abandonara a su hijo a fin de contraer nuevo matrimonio, máxime teniendo en cuenta que según la Ley judía una viuda con un hijo recién nacido debía esperar veinticuatro meses para volver a casarse $^{10}$. Hay que tener en cuenta que se trata de la versión que da la familia del marido difunto, ratificada por sus amigos. Por otro lado, uno de los testigos judíos, Jacó Çurí ¿era pariente de Mossé y Salamón? Habría que ser cautos a la hora de interpretar el suceso, ya que podría estar encubriendo una realidad bastante más compleja.

\section{6, diciembre 30}

Solí Carnerón, viuda de Salamón Çurí de Huesca, no quiere criar al hijo nacido póstumo después de enviudar, según testimonian los parientes del marido. Siempre según esta versión, la familia de Salamón se hace cargo de la crianza del niño en Uncastillo. Los adelantados de la aljama de Huesca solicitan una información acerca del paradero del niño.

AHPHuesca, prot. 377 (notario Domingo Frayella), f. ${ }^{\circ} 9 v-10 r$.

Recepcion de los testimonios delant los adelantados judios.

Eodem die, Osce [ilegible] presentes mí, Domingo Frayella, notario, e los testimonios dius scriptos. Los honorables Salomón Anoqua, trapero, lugarteniente de adelantado por Aym Figel, e Mossé Cohén, judíos, adelantados de la aljama de judíos, asín atendientes en dias passados Salamón Çurí, judío de la dita aljama, morió, e teniendo por muller a Solí Carnerón, judía, quedó prenyada, la cual aprés el dito Salamón Çurí muerto parió hun fillo, e por quanto ella se deliberaba casar, no quiso dar leche ni criar el dicho ninyo e assí se dezía algunos parientes del dito ninyo e del dito Salamón Çurí, quondam, se lo havían lebado a Huncastillo a criar, e que allá lo farían criar. E assí por cuanto los ditos adelantados havían de dar conto al senyor Rey e a otros juges e personas de aquella criatura, e por saber la verdat sobre aquello se querían informar e compellimiento e mandaron por Mossé Çurí, judío habitant en la villa de Huncastillo, e Leví Ya-

${ }^{10}$ Cf. el texto recogido en L. F. GIRón Blanc, Textos escogidos del Talmud (Barcelona 1998), pág. 58. 
yón, judío Osce, que allý presentes eran, que prestassen en su poder juramento sobre los Diez Mandamientos de dezir verdat de lo que fuesen interogados, que por odio, amor, temor, no dirían ni deposasen sino la verdat, los quales en continent juraron por Dios e los Diez Mandamientos de la Ley de Moysén en poder de los ditos adelantados de dir verdat, los cuales por el juramento que fecho havían respondieron e fueron interogados por los ditos adelantados e deposición segunt se sigue:

Primo, Mossé Çurí, judío habitant en la villa de Huncastillo, testimonio jurado e por el juramento interogado, respuso e dixo que era verdat en días passados quando morió el dito Salamón Çurí, hermano de este deposant, su muller, clamada Solí Carnerón, quedó prenyada, e aprés la dita su muller parió hun fillo e, por no perder el marido, ella no quiso dar leyt a la criatura. E assí, este deposant visto aquello, porque la criatura no se perdiese, deliberó de lebarlo a Huncastillo a la madre de este deposant e agüela del dito ninyo porque le diese ${ }_{10 \mathrm{r}}$ recaudo e lo fiziesse criar. E así, este deposant ampró para que lo acompanyase a Leví Yayón, judío de esta ciudat, e los dos levaron la dita criatura a Huncastillo, e la daron en poder de la madre d'este deposant, agüela del dito ninyo, la cual la dió a criar, e assí este deposant se fue a otras partes del regno a fazer sus negocios. E que más no ý sabe per jurament.

Leví Yayón, judío habitante en la ciudat de Huesca, testimonio jurado e por la jura interogado, respuso e dixo que era verdat en días passados este testimonio deposant de que fue muerto Salamón Çurí, judío de Huesca, fue amprado por Mossé Çuri, judío para levar hun ninyo que havía parido la muller del dito Salamón Çurí, clamada Solí Carnerón, judía, la cual no le havía querido dar leche, e que el dito Mossé deliberaba levarlo a su madre e agüela del dito ninyo a Huncastillo e assí el dito lebó el dito ninyo, et este testimonio fue con él e lo acompanyó fins allá, e dexaron la dita criatura a la agüela en Huncastillo, e allá la fazía criar, e que agora más no ý sabe.

Ex quipus, fecha la dita deposición, los ditos testimonios presentes, los testimonios dius scriptos presentes, los ditos adelantados, los ditos dayanes por descargo suyo requirieron por mí dito e infrascripto notario de las ditas deposiciones, fiziese e testificase carta pública una e muytas, large.

Testes: Pascual de Callén, labrador, Jacob Çurí, e Salamón Almaxech, judío, Osce.

7

Salamó Abentual narra la relación que ha mantenido con Mira Çurí y sin recato dice: « días passados yo haver participado assí carnalment como en otra manera [...] agora reconociendo aquesto seyer grant menosprecio e bilipendio mío, de mi muller e parientes míos»; como quiere evitar todo escándalo y daño 
para él y los suyos, se obliga a terminar desde el día de San Juan (24 de junio, y estamos a mediados de mayo) y durante cuatro años siguientes, su convivencia con Mira. A la niña que Mira tiene, y que no dice que sea hija suya, le ayudará con una cantidad simbólica: dos dineros. Es muy interesante tanto el que no diga (ni tampoco lo niegue) que la hija de Mira sea suya. Tampoco dice que tuviera descendencia de su mujer. Sorprende la intimidad de la relación que mantenía Salamó con Mira, que habitaba en la propia residencia de Salamó. Situaciones como esta eran toleradas por la sociedad judía.

\section{8, mayo 19}

Salamó Abentual promete dejar de vivir en concubinato con Mira Çurí durante un período de cuatro años.

AHPHuesca, prot. 326 (notario Pedro Palacio), f. ${ }^{\circ} 65 v$

\section{Reconocimiento.}

Die XVIIII, mensis madii, anno LXXXVIII Osce.

Eodem díe, que yo, Salamó Abentual, de mi cierta sciencia certificado e attendient y considerant en días passados yo haver participado, assí carnalment como en otra manera, con Mira de Çurí, judía Osce, agora reconosciendo aquesto seyer grant menosprecio e bilipendio mío, de mi muller e parientes míos, et quisiendo evitar todo scándalo e dapnache de mi cuerpo, y vivir como marido debe vivir con su mujer segunt la Ley nuestra lo manda, por tanto et alias, reconozco ahora por la hora et la hora por agora, yo dito Salamó Abentual et prometo, conviengo et me obligo por tiempo de quatro annyos primeros venideros del día de Sant Johan del mes de juniyo primero vinient en adelant, de no fazer participación alguna ansí carnal como en otra manera con la dita Mira de Çurí, ni comer, beber, estar, ni habitar dentro de casa de mí, dicho Salamó ni dentro de cassa de la dita Mira en tiempo alguno, ni darle dineros, ni bestirla, ni darle cosa ninguna directament ni indirecta, paladinament ni scondida, excepto a una ninya que tiene que le pueda dar valua de dos dineros e no más. Et finidos los quatro anyos, el dito reconocimient sea nullo e inválido, ansí como si feyto no fuesse y tomado en su liberación. Et a tener y cumplir todo lo susodito, obligo mi persona y bienes. Et juro por Dios e los Diez Mandamientos de la Ley de Moysén de tener y cumplir y no contravenir, dius me tome. Fiat large.

Testes: Johan de Araus et Abram Alcogunbriel, judío Osce. 
La fecha del último documento, 20 de mayo de 1489, coincide con el proceso que la Inquisición seguía contra un grupo de judíos acusados (algunos falsamente) de haber participado en la circuncisión del castellano Juan de Ciudad y su hijo en 1465, por el que fueron condenados y ajusticiados, asunto tratado en algún detalle por Baer primero, y luego por Durán, que aporta nueva evidencia documental, y Marín Padilla". En ese momento crítico, y aún cuando su nombre no figura entre los implicados directamente en el asunto de Juan de Ciudad, Martín Sánchez (ol. Jehudá Leví, alias Farizano) había optado por las aguas bautismales, que podrían haberle aliviado la condena. Es evidente que su conversión tiene que ver con la acción inquisitorial.

Al devolver parte de sus bienes a Martín, el juez de la Inquisición le perdona la «fadica», luego es que consideraba propiedad del Santo Oficio el ajuar de ropa y cacharros de cocina que había incautado al bautizado Martín. También podría tratarse de un reparto de los bienes conyugales, y cabe la posibilidad de que su esposa Cetí se hubiera resistido a darle sus bienes, y la Inquisición habría intervenido a favor del converso. Desconocemos el parentesco existente entre Cetí y Açach Abadías (¿padre-hija? ¿hermanos?).

Proporciono una transcripción de sus bienes para mostrar el detalle de parte de los objetos (no se trata de un inventario completo) que poseía un judío de familia conocida arraigada en la ciudad.

\section{9, mayo 20}

Relación de los bienes del converso Martín Sánchez (ol. Jehudá Leví, alias Farizano) que había recibido de su mujer Cetí Abadías y de Açach Abadías.

AHPHuesca, prot. 241 (notario Juan de la Fuente), f. $49 v-50 r$.

Albarán. Die predicte Osce.

Martín Sánchez nuevament babtizado e feyto cristiano e olim clamado Jehudá Leví, alias Farizano, habitante Osce, atorgo haver recebido de Cetí Abadías e Açach Abadías, judíos Osce, los bienes siguientes:

11 Y. F. BAER, Historia de los judios en la España cristiana (Barcelona 1998), págs. 731, 817 y 819; Durán, La judería de Huesca, págs. 121 y ss.; E. MARín PADILLA, «Relación judeoconversa durante la segunda mitad del siglo Xv en Aragón: nacimientos, hadas, circuncisiones», Sef 42 (1982), págs. 59-77. 
Primerament, un devant leyto de ropa ronçado.

Item, dos camisas de hombre.

Item, unas tovallyas blanquas.

Item, una tovallyola buena con listas cárdenas.

Item, un caxón viellyo.

Item, dos tovallyolas de estopa con un peçuelo.

Item, un pedaço de tela negra viella.

Item, una cerrallya de colpe con su clau.

Item, un candiler de sevo chiquo.

Item, un plat de malega [sic].

Item, otro chiquo.

Item, una raspa de [ilegible] chaures [sic].

Item, una caçolica de arambre.

Item, un cántaro de arambre.

Item, una taça crebada.

Item, una sartén.

Item, unas treudes ${ }^{12}$.

Item, un espado.

Item, una govellya gingebrada.

Item, un manto de mullyer negro.

Item, un çamarro de panyo viellyo.

Item, una capia.

Item, medias mangas [ilegible] viellyas.

Item, un par de mangas de tapet negras.

Item, un cuerpo de tela guarnido el tapiço y mangas de argent.

Item, una correa de argent con XXXI platón.

Item, un par de manillyas.

Item, dos espiellyos viellyos.

Item, dos cofrecicos.

Item, un collar de perlas LXXII.

${ }^{12}$ Es decir, tres patas de hierro para acercar los pucheros al fuego. 
${ }_{50 \mathrm{r}}$ Item, una caxa farinal viellya.

Item, una taula de pino.

Item, dos banquetas de posar.

Item, medio cofre.

Item, un anillyo sin piedra siellyo.

Item, dos linternas que tenía Pedro de Urroz.

Item, un anillyo sin piedra siellyo.

Los quales bienes fueron inventariados por la Santa Inquisición en poder e casa de la dita Cetí, estando mullyer del dito Jehudá Leví, los quales ut alegatur fueron adjudicados al dito Martín por micer Giert, juge de la dita Inquisición, e por la dita Inquisición fueron encomendados a los ditos Cetí e Acach, renunciant a toda excepción de fadica e porque sendo [ilegible] por contento e pagado a su propia voluntá atorgo el present público albarán.

Testes: maestre Ramón de Santa María e Abraham Exuén, judío habitante Osce.

Recibido: 04/04/2007

Aceptado: 01/03/2009 (versión final) 